\section{Why CAPS criteria are not diagnostic criteria?}

Kuemmerle-Deschner et $a l^{1}$ have recently published diagnostic criteria for cryopyrin-associated periodic syndrome (CAPS).

CAPS encompasses a group of very rare disorders with incompletely understood pathogenesis and diverse clinical presentations. The authors justify their efforts by claiming that there is a significant delay in diagnosis, which, in their opinion, is due to the lack of recognition and clear diagnostic criteria.

While the authors should be commended for their rigorous work, they may have overlooked the fact that they have developed classification criteria rather than diagnostic criteria. Recently, Aggarwall et $a l^{2}$ have pointed out the fundamental concerns related to diagnostic criteria in rheumatology. These concerns have led to the decision by the American College of Rheumatology (ACR) and the European League against Rheumatism to not endorse diagnostic criteria for rheumatic diseases anymore.

The most important shortcoming of the CAPS criteria in terms of their diagnostic potential is the absence of a 'true' gold standard for CAPS. CAPS criteria have been validated by the authors against the expert's opinion in a cohort including patients with a diagnosis of CAPS as well as other conditions that may or may not mimic CAPS, but are considered different. They report a sensitivity of $81 \%$ and a specificity of $94 \%$, which seems rather good but falls short if applied in a diagnostic context with extremely low prevalence: Given a prevalence of three in a million, a sensitivity of $81 \%$ and a specificity of $94 \%$ (and a positive likelihood ratio (LR+) of 13.5 (sensitivity/(1-specificity)) every true criteria-positive case of CAPS will be counterbalanced by 25000 false criteria-positive cases (according to Bayes' rule applied in this context, the post-test likelihood given a positive test (odds) equals the product of the $\mathrm{LR}+$ and the prevalence (odds)).

Our principal objection against diagnostic criteria in rheumatology may seem trivial, but will contextualise when one realises how diagnostic criteria will often be used in common clinical practice: as a checkbox, to be ticked by the diagnostician. Such a policy may lead to tremendous and potentially dangerous overdiagnosis as well as missing other relevant diagnoses and to overtreatment (eg, with biological drugs).

Recently, Radner et $a l^{3}$ have shown how the application of the 2010 ACR criteria for the classification of rheumatoid arthritis (which has a population prevalence, ie, more than 1000 times as high as that of CAPS) in a diagnostic context impacts specificity (which fell to only 61\%) of these criteria.

To us it seems that patients with CAPS or conditions mimicking CAPS are not served by using the CAPS criteria in a diagnostic context. The authors should rectify their claim that they have developed diagnostic criteria to avoid misinterpretation by clinicians and rename them as classification criteria, implying that these can only be applied in patients with a diagnosis of CAPS.

\section{Robert BM Landewé, ${ }^{1,2}$ Désirée MFM van der Heijde ${ }^{3,4}$}

${ }^{1}$ Department of Rheumatology \& Clinical Immunology, Amsterdam Rheumatology \& immunology Center, Amsterdam, The Netherlands

${ }^{2}$ Department of Rheumatology, Zuyderland Medical Center, Heerlen, The Netherlands

${ }^{3}$ Deprtament of Rheumatology, Leiden University Medical Center, Leiden, The Netherlands

${ }^{4}$ Diakonhjemmet Hospital, Oslo, Norway

Correspondence to Professor Robert BM Landewé, Department of Rheumatology, Zuyderland Medical Center, Heerlen 6311PP, The Netherlands; landewe@rlandewe.nl

Correction notice This article has been corrected since it published Online First. The article type has been changed to correspondence.

Contributors RBML and DvdH have drafted the manuscript, are responsible for the content and have approved the final version for submission and review.

\section{Competing interests None.}

Provenance and peer review Not commissioned; internally peer reviewed.

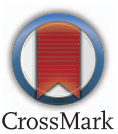

To cite Landewé RBM, van der Heijde DMFM. Ann Rheum Dis 2017;76:e7.

Received 11 October 2016

Accepted 13 October 2016

Published Online First 17 November 2016

Ann Rheum Dis 2017;76:e7. doi:10.1136/annrheumdis-2016-210656

\section{REFERENCES}

1 Kuemmerle-Deschner JB, Ozen S, Tyrell PN, et al. Diagnostic criteria for cryopyrin-associated periodic syndrome (CAPS). Ann Rheum Dis 2016; Published Online First: 4 Oct 2016.10.1136/annrhuemdis-2016-209686

2 Aggarwall R, Ringold S, Khanna D, et al. Distinctions between diagnostic and classification criteria? Arthritis Care Res (Hoboken) 2015;67:891-7.

3 Radner H, Neogi T, Somolen J, et al. Performance of the 2010 ACR/EULAR classification criteria for rheumatoid arthritis: a systematic literature review. Ann Rheum Dis 2014;73:114-23. 